\title{
Exploring the ATP-binding site of P2X receptors
}

\section{Thierry Chataigneau *, Damien Lemoine and Thomas Grutter}

Equipe de Chimie et Neurobiologie Moléculaire, Laboratoire de Conception et Application de Molécules Bioactives, Faculté de Pharmacie, UMR 7199 CNRS, Université de Strasbourg, IIlkirch, France

Edited by:

Baljit S. Khakh, University of

California Los Angeles, USA

\section{Reviewed by:}

Damien Samways, Clarkson

University, USA

Richard Evans, University of

Leicester, UK

\section{*Correspondence:}

Thierry Chataigneau, Equipe de

Chimie et Neurobiologie

Moléculaire, Laboratoire de

Conception et Application de

Molécules Bioactives, Faculté de

Pharmacie, UMR 7199 CNRS,

Université de Strasbourg, 74 route

du Rhin, 67400 IIIkirch, France

e-mail: thierry.chataigneau@

unistra.fr
P2X receptors are ATP-gated non-selective cation channels involved in many different physiological processes, such as synaptic transmission, inflammation, and neuropathic pain. They form homo- or heterotrimeric complexes and contain three ATP-binding sites in their extracellular domain. The recent determination of X-ray structures of a P2X receptor solved in two states, a resting closed state and an ATP-bound, open-channel state, has provided unprecedented information not only regarding the three-dimensional shape of the receptor, but also on putative conformational changes that couple ATP binding to channel opening. These data provide a structural template for interpreting the huge amount of functional, mutagenesis, and biochemical data collected during more than fifteen years. In particular, the interfacial location of the ATP binding site and ATP orientation have been successfully confirmed by these structural studies. It appears that ATP binds to inter-subunit cavities shaped like open jaws, whose tightening induces the opening of the ion channel. These structural data thus represent a firm basis for understanding the activation mechanism of $\mathrm{P} 2 \mathrm{X}$ receptors.

Keywords: ATP, P2X receptors, binding site, gating, crystal structure, mutagenesis, engineered site-directed labeling

\section{INTRODUCTION}

ATP-gated P2X receptors are involved in a variety of physiological processes such as fast synaptic transmission, contraction of smooth muscle, regulation of neurotransmitter release, inflammation, and pain sensation (Surprenant and North, 2009; Burnstock, 2012; Khakh and North, 2012). They are also implicated in neurodegenerative and neuropsychiatric disorders (Burnstock, 2008, 2012; Lemoine et al., 2012) and are thus considered as important therapeutic targets.

P2X receptors belong to the super family of ligand-gated ion channels (LGICs), but they differ significantly from the other LGIC members -the Cys-loop and ionotropic glutamate receptors- by their molecular architecture and stoichiometry (Lemoine et al., 2012). They are trimeric channels permeable to cations with the exception of $\mathrm{P} 2 \mathrm{X} 5$ receptor which is also permeable to chloride ions (Ruppelt et al., 2001; Bo et al., 2003; Kaczmarek-Hajek et al., 2012). In mammals, seven members (P2X1-7) have been cloned that arrange in homotrimeric or heterotrimeric P2X receptors and they are all characterized by an extracellular loop domain (ectodomain) and two transmembrane segments (TM1 and TM2) which are terminated by intracellular $\mathrm{N}$ - and C-termini (Coddou et al., 2011; Kaczmarek-Hajek et al., 2012; Lemoine et al., 2012).

Following ATP binding in the ectodomain which is about 280 amino acids long, a fast and large conformational change occurs throughout the receptor that results in pore opening (Evans, 2009; Jiang et al., 2013). Many different strategies such as site-directed mutagenesis, electrophysiological recordings, fluorescence-based approaches, and X-ray crystallography have contributed to the understanding of the mechanism by which ATP-binding is coupled to gating. An initial approach was to compare the binding site of P2X receptors with other ATP-binding proteins but it rapidly became evident that there is a lack of sequence homology between P2X receptors and these proteins; for instance, $\mathrm{P} 2 \mathrm{X}$ receptors do not contain the Walker motif, which characterizes other ATPbinding proteins (Walker et al., 1982). However, the role of the conserved amino acids of the extracellular loop has been systematically investigated using site-directed mutagenesis. This method has led to the identification of short domains and specific residues such as lysine, arginine, and phenylalanine putatively involved in ATP recognition. But to clearly distinguish the participation of these residues in the recognition of ATP from the channel gating, which can also lead to loss of function, complementary methods have been developed. In this context, cysteine-reactive chemicals as well as photosensitive or cysteine-reactive ATP derivatives have been used to explore the putative residues involved in ATP recognition. Altogether, these investigations have yielded substantial information for the modeling of the interaction between ATP and its specific binding site.

The recent determination of X-ray structure of the zebrafish (zf) P2X4 receptor in a closed state and in an ATP-bound openchannel state confirmed many key experimental data, including the mechanism of ATP binding (Figure 1). It is now possible to understand at an unprecedented level of precision the mechanism by which ATP is selectively recognized. Indeed, as detailed later, the ATP-bound open-channel structure revealed that the ATP triphosphate tail is coordinated by the residues K70, K72, K316, N296, and R298 (zfP2X4 numbering), while K193 residue indirectly interacts with the $\alpha$-phosphate group. The residues T189, L191, and I232 are responsible for the coordination of the adenine moiety of ATP whereas L217 is involved in the recognition of the ribose ring of ATP. Therefore, both 


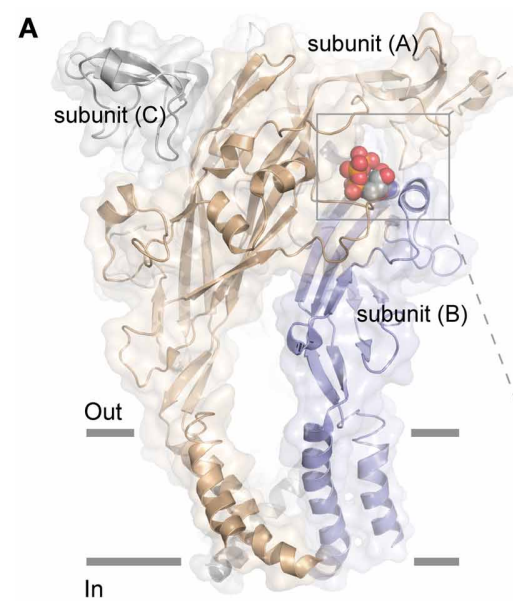

FIGURE 1 | Crystal structure of zfP2X4 receptor bound to ATP. (A) Lateral view of the trimeric structure. Each subunit, displayed in both surface and ribbon representation, is shown in a different color. Only one bound ATP molecule is

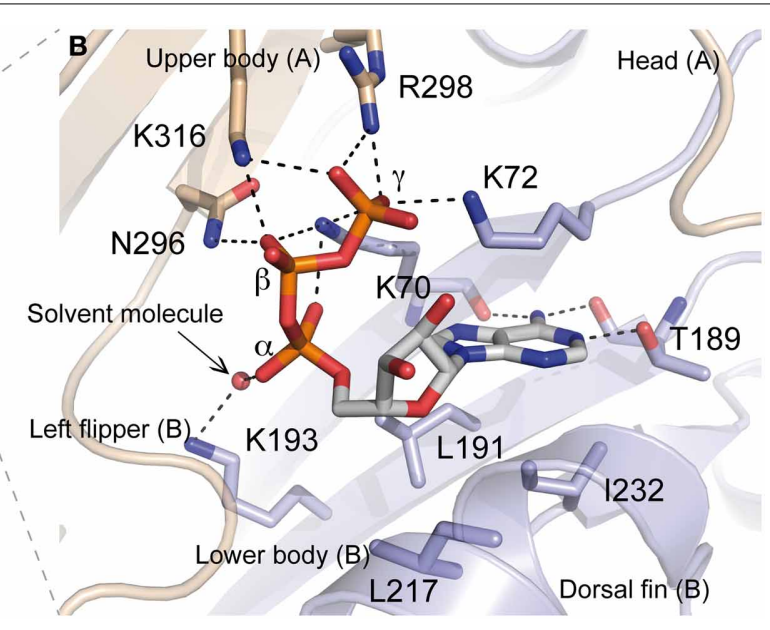

shown. (B) Close-up view of the ATP-binding site. The oxygen atom from the solvent molecule (glycerol) is shown in sphere representation. Black dashed lines indicate hydrogen bonding. (Modified from Hattori and Gouaux, 2012). positively charged and hydrophobic amino acid residues that belong to different structural domains of the receptor surround bound ATP molecule. Because the overall structure of each receptor subunit resembles a "leaping dolphin," these domains were named upper body from chain A, and lower body and dorsal fin from chain B (Figure 1B). Decoding the mechanism of this exquisite specificity will certainly be useful to designing new drugs for these receptors recognized as therapeutic targets.

In this review, we present different experimental approaches that have been used to explore the ATP-binding site in $\mathrm{P} 2 \mathrm{X}$ receptors and discuss the results in the light of the recent ATP-bound crystal structure.

\section{MUTAGENESIS-BASED ANALYSIS OF ATP BINDING SITE: A COMPARISON WITH THE CRYSTAL STRUCTURE OF THE ATP-BOUND zfP2X4 RECEPTOR}

Considering the lack of sequence homology between $\mathrm{P} 2 \mathrm{X}$ receptors and other ATP binding proteins, the analysis of the binding site has been performed mainly with the help of systematic sitedirected mutagenesis combined with electrophysiological characterization to explore the role of conserved residues in the binding site of ATP in P2X receptors (Evans, 2009). In this long quest, site-directed mutagenesis of conserved ectodomain residues has been one of the most employed approaches. ATPinduced responses have been mostly assessed for P2X receptors composed of mutated subunits heterologously expressed in either HEK 293 cells with the patch-clamp technique or Xenopus laevis oocytes with the use of two-electrode voltage-clamp recordings (Fischer et al., 2007; Evans, 2009, 2010). A role of the amino acids in the binding of ATP has been evaluated by the alteration of ATP potency, a combined measure between affinity and gating (Roberts and Evans, 2004).

\section{ROLE OF POSITIVELY AND NEGATIVELY CHARGED RESIDUES}

It was initially suggested that highly conserved positively charged residues of the extracellular loop of $\mathrm{P} 2 \mathrm{X}$ receptors could participate to the binding of negatively charged ATP through coordination of the phosphate groups as found for lysine residues in the Walker motif of other ATP-binding proteins (Ennion et al., 2000). Positively charged residues of human (h) P2X1 and rat (r) P2X2 receptors were mainly substituted for alanine to neutralize the positive charges whereas substitution with arginine allowed the conservation of the positive charge for comparison (see Table 1). Pioneering studies identified positively charged amino acids such as lysine residues in hP2X1 and rP2X2 receptors, corresponding to residues K70, K72, K193, and K316 in zfP2X4 receptor, as crucial residues for the binding of ATP (Ennion et al., 2000; Jiang et al., 2000). As initially shown by Digby et al. (2005), the KxKG sequence including the two amino acids K70 and K72 (zfP2X4 numbering), which is a highly conserved motif of $\mathrm{P} 2 \mathrm{X}$ receptors, plays a major role in ATP recognition; these findings were confirmed in $\mathrm{hP} 2 \mathrm{X} 1, \mathrm{hP} 2 \mathrm{X} 2$, and hP2X3 receptors (Fischer et al., 2007; Roberts et al., 2008; Allsopp et al., 2011; Bodnar et al., 2011) as well as in rP2X1, $\mathrm{rP} 2 \mathrm{X} 2, \mathrm{rP} 2 \mathrm{X} 3$, heteromeric $\mathrm{rP} 2 \mathrm{X} 2 / 3, \mathrm{rP} 2 \mathrm{X} 4$, and $\mathrm{rP} 2 \mathrm{X} 7$ receptors (Wilkinson et al., 2006; Yan et al., 2006; Zemkova et al., 2007; Roberts et al., 2008; Jiang et al., 2011). The participation of residues K193 and K316 (zfP2X4 numbering) to agonist recognition has also been described in hP2X1, hP2X2, hP2X3, and hP2X7 receptors (Worthington et al., 2002; Roberts and Evans, 2007; Roberts et al., 2008, 2009; Bodnar et al., 2011), as well as in $\mathrm{rP} 2 \mathrm{X} 2, \mathrm{rP} 2 \mathrm{X} 2 / 3$ and $\mathrm{rP} 2 \mathrm{X} 4$ receptors (Yan et al., 2005; Wilkinson et al., 2006; Yan et al., 2006; Zemkova et al., 2007; Roberts et al., 2008; Jiang et al., 2011). It is noteworthy that lysine residues appear to also have a highly conserved role in non-mammalian $\mathrm{P} 2 \mathrm{X}$ receptors since the two mutations K67A and K289A (at positions equivalent to K72 and K316 of zfP2X4, respectively) significantly decreased the ATP potency of the amoeba Dictyostelium discoideum P2X receptor (Fountain et al., 2007).

Thiol-reactive methanethiosulfonate reagents such as (2-aminoethyl)methanethiosulfonate hydrobromide (MTSEA, positively charged compound) and sodium (2-sulfonatoethyl) 
Table 1 | Effects of mutations on ATP-induced activation of P2X receptors.

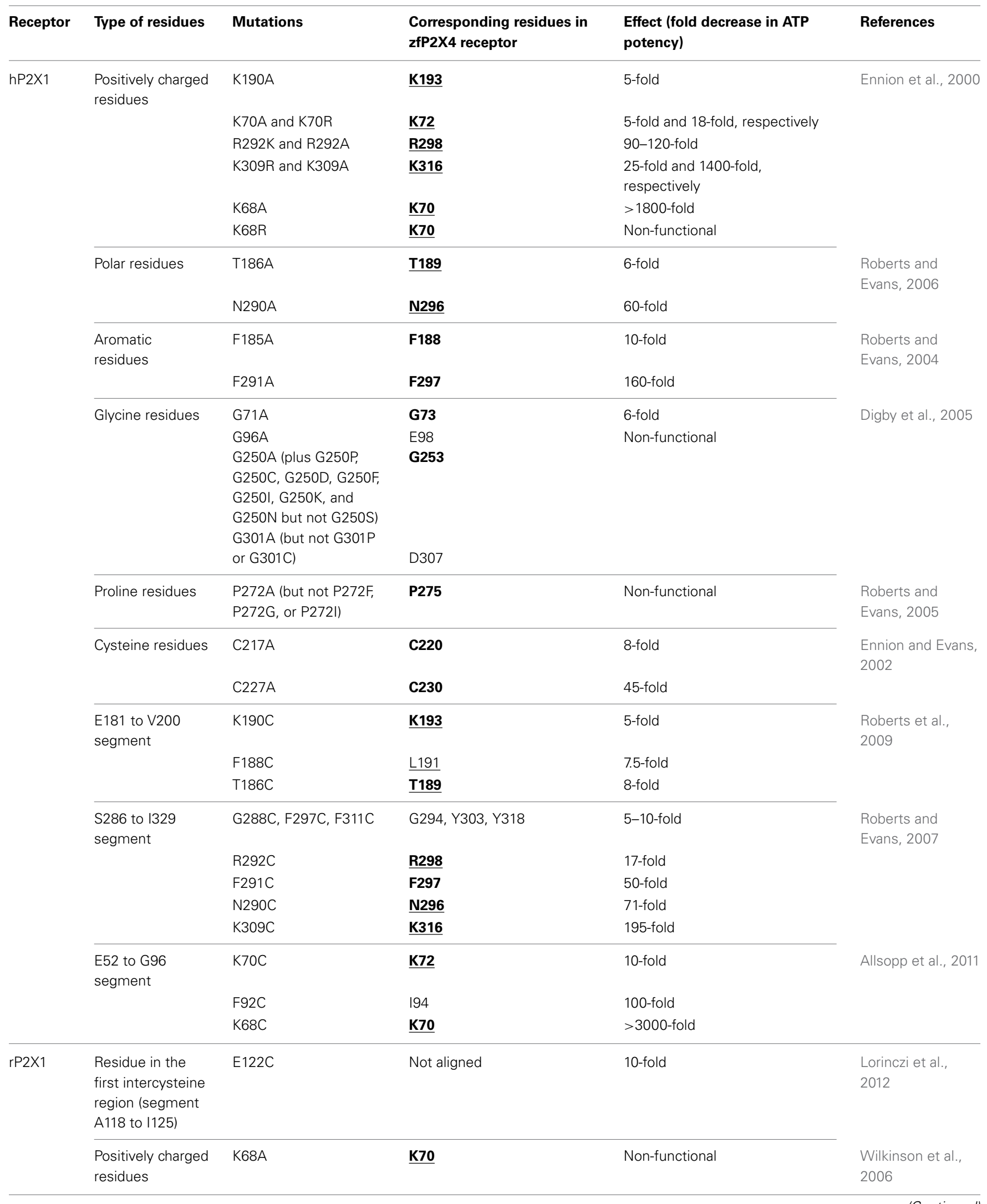




\section{Table 1 | Continued}

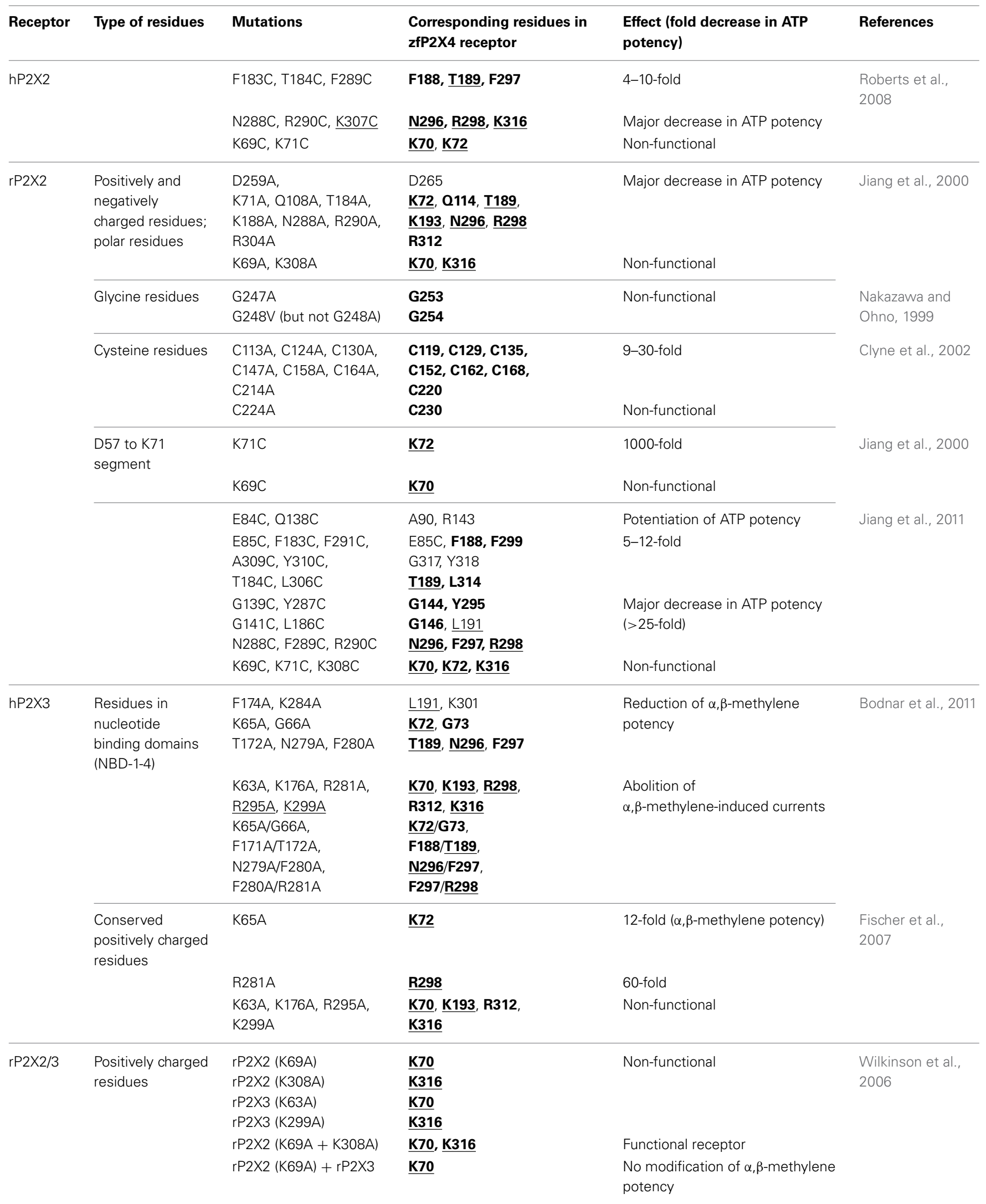


Table 1 | Continued

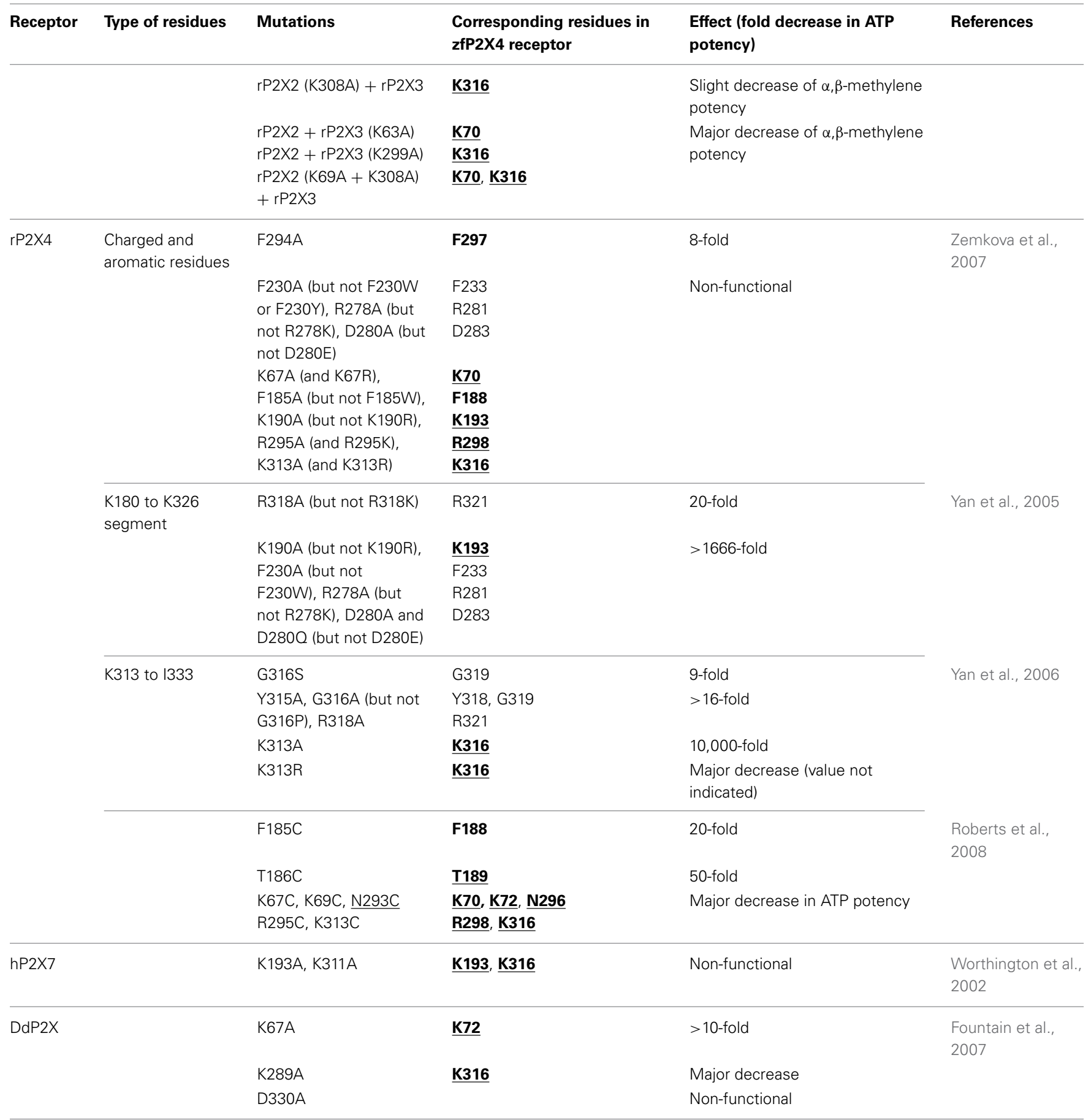

The results have been classified according to an increasing rank of order of inhibition for the mutations indicated in each study.

For the corresponding residues in the zfP2X4 crystal structure:

- conserved residues are in bold;

- underlined residues have been identified to participate to the binding of ATP;

- normal characters indicate residues that are not conserved among species.

The modification of $\alpha, \beta$-methylene potency is also indicated. Decrease of agonist potency not exceeding 5 -fold has not been taken into account.

The lack of function of G250A-containing hP2X1 receptors most likely results from a failure in normal processing of the receptor (Digby et al., 2005). K307C-containing hP2X2 receptors were expressed at lower levels in cells (Roberts et al., 2008). R295A-, and K299A-containing hP2X3 receptors were expressed at lower levels in cells (Bodnar et al., 2011). F230A-containing rP2X4 receptors were expressed at lower levels (Zemkova et al., 2007). A reduction of trafficking of N293C-containing rP2X4 receptors to the cell surface has been proposed (Roberts et al., 2008). 
methanethiosulfonate (MTSES, negatively charged compound) have proved very useful in examining the role of charges in the ATP-binding site (Jiang et al., 2000; Roberts and Evans, 2007; Roberts et al., 2008, 2009). Indeed, this strategy is based on the fact that these compounds have the capacity to form disulfide bonds when amino acid residues are strategically substituted with cysteine; this procedure consequently modifies the recognition of ATP if the mutation is performed at crucial residues in the binding site. Interestingly, positively charged MTSEA introduces a positively charged side chain of similar length to that of lysine and thus helps to verify the critical role of positively charged residues in the recognition of the phosphate groups (Fountain and North, 2006). In this context, mutational studies and MTS reagents-based experiments have shown the importance of positively charged residues for ATP binding and action, in particular lysine residues of $\mathrm{hP} 2 \mathrm{X} 1, \mathrm{rP} 2 \mathrm{X} 2$, and $\mathrm{rP} 2 \mathrm{X} 4$ corresponding to the residues K70, K72, K193, and K316 of zfP2X4 (Roberts and Evans, 2007; Roberts et al., 2008, 2009; Allsopp et al., 2011).

In addition to lysine, numerous studies have also highlighted the major role of arginine residues in $\mathrm{hP} 2 \mathrm{X} 1, \mathrm{hP} 2 \mathrm{X} 3, \mathrm{rP} 2 \mathrm{X} 2$, and rP2X4 receptors (all corresponding to R298 in zfP2X4, Table 1) in agonist recognition by interaction with a phosphate group of ATP (Ennion et al., 2000; Jiang et al., 2000; Fischer et al., 2007; Zemkova et al., 2007). The contribution of this residue to the ligand binding site has also been confirmed using partial agonists such as $2^{\prime}, 3^{\prime}$-O-(4-benzoyl)-ATP (BzATP) and P(1),P(5)di(adenosine $5^{\prime}$ )-pentaphosphate (Ap(5)A) in hP2X1 (Roberts and Evans, 2004). It is notable that a recent study in rP2X2 receptor has also indicated that a salt bridge between the residues R290 (R298 in zfP2X4) and E167 stabilized the closed state of the receptor and that, after spatial rearrangement and release of this electrostatic coupling, a new ionic interaction took place between R290 and ATP, contributing to the coordination of ATP in its binding site (Hausmann et al., 2013).

All these results have now been confirmed by the recent resolution of the structure of the ATP-bound zfP2X4 receptor (Figure 1) (Hattori and Gouaux, 2012). This study revealed how the positively charged residues $\mathrm{K} 70, \mathrm{~K} 72, \mathrm{~K} 316$, and R298 are critically involved in direct coordination of the ATP triphosphate tail, while K193 residue indirectly interacts with the $\alpha$-phosphate group through a glycerol solvent molecule (used for crystallization purpose). It has been proposed that water molecules substitute glycerol under physiological conditions (Hattori and Gouaux, 2012) (Figure 1B). The X-ray structure also shows how the three phosphate groups of ATP interact with the positively charged residues, providing a plausible explanation of why ADP has almost no effect on the activation of P2X receptors (Hattori and Gouaux, 2012). Furthermore, it is noteworthy that K70 residue, for which it has been shown that alanine mutation induced the largest inhibitory effect on ATP potency (see Table 1), occupies a very crucial position in ATP binding since it coordinates oxygen atoms of the $\alpha, \beta$, and $\gamma$ phosphate groups (Figure 1B). In addition, the $\mathrm{X}$-ray structures of zfP2X4 definitively confirmed the intersubunit location of the ATP-binding site (Kawate et al., 2009; Hattori and Gouaux, 2012). The identification of the role of the conserved positively charged residues K68, K70, R292, and K309 (hP2X1 receptor) in ATP recognition initially led to the proposition that these residues, organized in two clusters, could form the ATP binding site by interacting either within a $\mathrm{P} 2 \mathrm{X}$ receptor subunit or between adjacent subunits (Ennion et al., 2000). It was thereafter proposed that the heteromeric $\mathrm{rP} 2 \mathrm{X} 2 / 3$ receptor was probably composed of one $\mathrm{rP} 2 \mathrm{X} 2$ and two $\mathrm{rP} 2 \mathrm{X} 3$ subunits and that the residues from two different subunits were able to interact in the ATP binding site (Wilkinson et al., 2006). Another decisive demonstration for the intersubunit position of the ATP binding site in $\mathrm{P} 2 \mathrm{X}$ receptors came from the observation that the mutations $\mathrm{K} 68 \mathrm{C}$ and F291C in rP2X1 (corresponding to K70 and F297 in zfP2X4 receptor, respectively) led to the formation of disulfide cross-link into trimers (Marquez-Klaka et al., 2007). In addition, it was shown that the disulfide bond formation between K68C and F291C was prevented in the presence of ATP (Marquez-Klaka et al., 2007). This study clearly demonstrated that residues from adjacent subunits contribute together to the formation of the ATP-binding site in $\mathrm{P} 2 \mathrm{X}$ receptors.

It is assumed that ATP forms complexes with $\mathrm{Mg}^{2+}$ (Ashcroft and Gribble, 1998; Ennion et al., 2001; Li et al., 2013). For this reason, it has been postulated that the negatively charged amino acids of P2X receptors could contribute to the binding of ATP (Ennion et al., 2001). However, none of the mutations of the conserved negatively charged residues (aspartate and glutamate) had an effect on ATP potency, indicating that they are not involved in ATP recognition in hP2X1 (Ennion et al., 2001). In agreement, no negatively charged residues were found to interact directly with ATP in the crystal structure (Figure 1B). In addition, no $\mathrm{Mg}^{2+}$ ions were resolved near bound ATP, a result fully consistent with recent data showing that $\mathrm{ATP}^{4-}$ activates all subtypes of homomeric P2X receptors, whereas MgATP ${ }^{2-}$ activates only P2X1 and P2X3, but not P2X2 and P2X4 receptors (Li et al., 2013). Thus, $\mathrm{ATP}^{4-}$ seems to be the primary ionic form that activates P2X receptors.

\section{POLAR AMINO ACIDS}

The possibility that conserved polar residues such as glutamine, asparagine, and threonine play a role in ATP recognition at the ATP binding site had also been investigated because they may form hydrogen bonds with ATP (Roberts and Evans, 2006). As shown in Table 1, only mutations of residues corresponding to T189 and N296 (zfP2X4 numbering) had a significant effect on ATP potency. The residue T189 is in part responsible for the coordination of the adenine moiety of ATP whereas N296 participates to the coordination of the $\beta$-phosphate groups (Figure 1B) (Hattori and Gouaux, 2012). It must be noticed that the mutations with alanine at the residues corresponding to T189 and N296 in zfP2X4 had already been shown to significantly reduce ATP potency in rP2X2 receptors (see Table 1) (Jiang et al., 2000).

\section{AROMATIC AMINO ACIDS}

The fact that aromatic residues have been identified to play key roles in the coordination of ATP in other ATP-binding proteins stimulated the investigation of alanine-based substitution of conserved extracellular aromatic amino acids in P2X receptors (Roberts and Evans, 2004). It was concluded that the residues corresponding to F188 and F297 (zfP2X4 numbering) are involved in the coordination of ATP (see Table $\mathbf{1}$ ) whereas the substitutions 
of both tryptophan and tyrosine residues had no effect (Roberts and Evans, 2004). It is noteworthy that the residue F297 belongs to the highly conserved NFR sequence in which the two conserved amino acids (N296 and R298 in zfP2X4) participate to the coordination of the $\beta$ - and $\gamma$-phosphate groups of ATP, respectively (Hattori and Gouaux, 2012). However, the crystal structure revealed that the side chain of F297 does not interact directly with ATP, but it may help to contribute to the general shape of the binding site. Altogether, these data confirm the importance of the NFR sequence in ATP binding (Jiang et al., 2000, 2011; Roberts and Evans, 2004, 2006, 2007; Fischer et al., 2007; Marquez-Klaka et al., 2007; Zemkova et al., 2007; Roberts et al., 2008; Bodnar et al., 2011). Furthermore, as determined in $\mathrm{rP} 2 \mathrm{X} 1$ receptors, the residue $\mathrm{F} 291$ (F297 in $\mathrm{zfP} 2 \mathrm{X} 4$ ) contributes to the formation of the ATP binding site between neighboring subunits in $\mathrm{P} 2 \mathrm{X}$ receptors (Marquez-Klaka et al., 2007). The mutation of the surrounding amino acids (F289A and F293A) had, however, no effect suggesting that only the conserved NFR sequence has importance in this region (Roberts and Evans, 2004).

Another region between residues F185 and K190 in hP2X1 (region F188-K193 in zfP2X4) has also been indicated to contribute to the effect of ATP (Roberts and Evans, 2004). Indeed, at the neighboring position to residue T186 of hP2X1 (T189 in zfP2X4), F185 (F188 in zfP2X4) has been shown to participate to agonist-evoked conformational change of the receptor as determined with MTS experiments (Roberts et al., 2009) but this residue does not directly interact with ATP according to the crystal structure (Hattori and Gouaux, 2012).

The particular position of the two phenylalanine residues probably explains the important alteration of ATP potency after their substitution as it is estimated that adjacent residues are also involved in the control of ATP binding (Bodnar et al., 2011).

\section{GLYCINE, PROLINE, AND CYSTEINE RESIDUES}

The small and achiral amino acid glycine commonly confers flexibility to protein structures. In addition, in $\mathrm{P} 2 \mathrm{X}$ receptors the possibility that the GGxxG motif (residues 250-254 in hP2X1 numbering) participates in ATP binding was investigated because it has similarities to the conserved GxGxxG motif found in around $95 \%$ of human protein kinases and nucleotide-binding proteins (Spitaler et al., 2000; Digby et al., 2005). Studies designed to investigate the putative role of these conserved glycine residues in the extracellular loop concluded that these amino acids do not participate to the ATP-binding site in hP2X1 (Ennion and Evans, 2002; Digby et al., 2005; Roberts and Evans, 2005). Interestingly, mutation of the glycine residue corresponding to G253 (zfP2X4 numbering) induces the formation of non-functional hP2X1 and rP2X2 receptors (Nakazawa and Ohno, 1999; Digby et al., 2005). These results can be explained by the fact that the mutation induces a defect in the level of expression of the receptor at the cell surface (Digby et al., 2005).

Proline residues have been proposed to play a major role in the secondary structure of proteins (Brandl and Deber, 1986; Yamaguchi et al., 1999; Sansom and Weinstein, 2000; Labro et al., 2003; Roberts and Evans, 2005). The alanine-based substitutions of proline residues of the extracellular loop of hP2X1 had only negligible effects on ATP potency indicating that these residues are not involved in the ATP-binding site (Roberts and Evans, 2005). Nevertheless, mutations at P272 in hP2X1 produced variable effects on ATP-potency depending on the nature of the residue used for the substitution suggesting that the effect of ATP is possibly sensitive to the variation of conformation in this region of the receptor (Roberts and Evans, 2005). Because this residue is localized at around $18 \AA$ from the ATP-binding site, it can be postulated that it is more probably involved in the gating of the pore (Figure 2).

Ten conserved cysteine residues are present that can form disulfide bonds in the extracellular loop of P2X receptors; their alanine-based substitution had some effects on ATP potency and the mutations at positions homologous to the residue C230 (zfP2X4 numbering) considerably reduced ATP-induced responses (Clyne et al., 2002; Ennion and Evans, 2002). The crystal structure confirmed that the two residues C220 and C230 form a disulfide bond, which rigidifies the dorsal fin, a critical component of the ATP-binding site (Figure 2).

\section{GROUPS OF AMINO ACIDS ORGANIZED IN NUCLEOTIDE BINDING DOMAINS}

The alanine-based substitution of residues from four defined nucleotide binding domains of hP2X3 has indicated that the mutation of residues adjacent to identified amino acids, which are crucial for agonist response (i.e., lysine, asparagine, threonine), induced further alterations of agonist potency, in this case

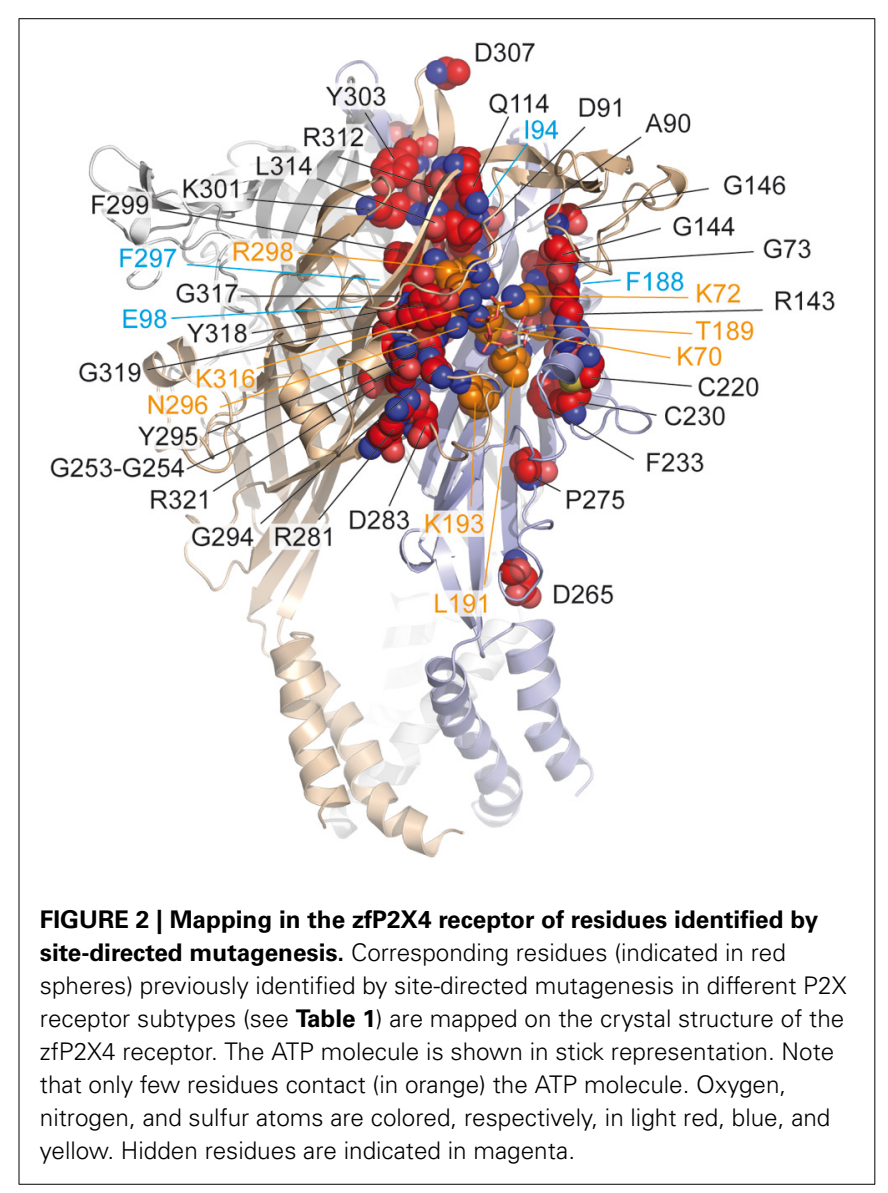


$\alpha, \beta$-methylene ATP (see Table 1) (Bodnar et al., 2011). Indeed, the double mutants K65A/G66A, F171A/T172A, N279A/F280A, and F280A/R281A (K72/G73, F188/T189, N296/F297, and F297/R298 in zfP2X4 receptor, respectively) were all insensitive to $\alpha, \beta$-methylene ATP, in contrast to the single mutants which were responsive to the agonist (Bodnar et al., 2011). These results have led to the concept that groups of amino acids, rather than individual amino acids, are responsible for the recognition of ATP (Bodnar et al., 2011). The nucleotide binding domains overlap the essential residues for ATP binding, as determined from the X-ray structure of ATP-bound zfP2X4 receptor (Figure 2).

With the characterization of hundreds of alanine and cysteine mutants in the extracellular domain of $\mathrm{P} 2 \mathrm{X}$ receptors, it was found that several mutations induced a decrease in ATP potency and were found close to the ATP molecule. However, among these mutations, only some (less than ten) correspond to crucial residues directly involved in ATP binding (Figure 2). In an MTS-based study, it was postulated that non-conserved residues play a regulatory role in the effect of ATP (Roberts et al., 2008). The participation of several non-conserved residues in ATP recognition was revealed by the crystal structure of the ATP-bound zfP2X4 receptor (Hattori and Gouaux, 2012). However, to our knowledge, the mutation-based analysis failed to determine two residues i.e., I232 and L217 (zfP2X4 numbering) which are involved, respectively, in the recognition of the adenine base and ribose ring of ATP (Figure 1B). In addition, the main limitation of site-directed mutagenesis was the difficulty to distinguish clearly the direct modification of ATP binding from alterations in channel gating, which can also lead to a loss of function (Colquhoun, 1998). Indeed, ATP potency is dependent upon both the affinity and gating. The mutations of residues which do not participate in ATP recognition in the binding site can, however, lead to changes in ATP potency because these residues are able to induce conformational alterations associated with gating of the pore in response to ATP binding (Evans, 2010). For this reason, complementary methods have been employed to distinguish clearly residues participating in the ATP-binding site from those involved in gating. In this context, allosteric reporter mutations in combination with single-channel recordings, cysteine-reactive chemicals as well as ATP-derivatives with photosensitive or cysteine-reactive moieties have been used to explore the putative residues involved in the coordination of both the negatively charged phosphate groups and the adenine ring of ATP. Altogether, these investigations provided new insights into the understanding of the mechanism of ATP-binding.

\section{ADDITIONAL METHODS FOR THE INVESTIGATION OF THE ATP-BINDING SITE ALLOSTERIC REPORTER MUTATIONS}

The first evidence distinguishing ATP binding from gating in P2X receptors was provided by Cao et al. (2007), where the authors combined single-channel recordings and the use of a mutated receptor considered as an "allosteric reporter." They took advantage of the fact that the deep pore mutation T339S in the $\mathrm{P} 2 \mathrm{X} 2$ receptor produced spontaneous openings of the channel in the absence of agonist. This mutation most likely modifies the allosteric equilibrium between the closed and open states, and thus reports gating properties. Introducing the K69A or K308A mutation into the T339S background, the authors showed that K308A mutation alters considerably the spontaneous channel openings and consequently the gating properties of the receptor, whereas the nearby K69A mutation leaves these spontaneous activities unaffected (Cao et al., 2007). Given the fact that both mutations do not respond to ATP, these elegant experiments identified K69 as a critical residue for direct recognition of ATP and $\mathrm{K} 308$ as important one for channel gating, in addition to its contribution to the binding site. As stated above, the crystal structure definitively confirmed the particular location of K69 (K70 in $\mathrm{zfP} 2 \mathrm{X} 4)$ in coordination of the phosphate tail, thus validating such a "genetic" approach, which can be applied to other ion channels.

\section{STRATEGY OF SITE-DIRECTED AFFINITY LABELING}

In the attempt to precisely localize the ATP-binding site, a "chemical" strategy has been developed which consists of site-directed affinity labeling to create covalent bonds between a synthesized ATP-derived thiol-reactive rP2X2 agonist, 8-thiocyano-ATP (NCS-ATP), and single cysteine mutants engineered in the putative binding cavities of the $\mathrm{rP} 2 \mathrm{X} 2$ receptor (Figure 3A) (Foucaud et al., 2001; Jiang et al., 2011). The 26 residues to be substituted were chosen on the basis of rP2X2 homology model because they protrude in the binding cavity (Jiang et al., 2010). By combining whole-cell and single-channel recordings, it was shown that NCS-ATP labeled only two cysteine mutants, N140C and L186C, which are separated by about $18 \AA$ in the closed state of the receptor. While irreversible binding at N140C decreased both ATP efficacy and open probability $\left(\mathrm{NP}_{o}\right)$ of ATP-activated rP2X2 receptors, labeling of $\mathrm{L} 186 \mathrm{C}$ induced a potentiation of the ATP responses (Jiang et al., 2011). It was proposed that the potentiating effect would occur only at one or two of the three binding pockets per receptor, producing strong cooperativity for further ATP binding (Jiang et al., 2011). Considering all these results, models were constructed in which the residues previously identified by site-directed mutagenesis to be crucial for ATP recognition (see previous chapter) appeared in close proximity to docked NCS-ATP (Jiang et al., 2011). From this work, it was concluded that the inter-subunit cavities found in the closed X-ray structure of zfP2X4 (Kawate et al., 2009) correspond to the ATP-binding sites and that this strategy has helped define the involvement of two non-conserved residues, N140 and L186 in the coordination of the adenine ring of ATP (Jiang et al., 2011) (Figure 3B). The ATP-bound crystal structure of zfP2X4 confirms the close proximity (4.3 $\AA$ ) of L191 (L186 in rP2X2) to the ATP site and shows that this residue is indeed involved in hydrophobic interactions with the adenine base of ATP (Figure 3C) (Hattori and Gouaux, 2012). However, it is surprising to note that the other NCS-ATP labeled residue, $\mathrm{N} 140$, (corresponding to D145 in zfP2X4) is located at $\sim 14$ $\AA$ from position 8 of the adenine ring of ATP (Figure 3C). Interestingly, this residue is close to the region that accommodates NF770, a suramin derivative that is the most potent P2X2 receptor antagonist described so far (Wolf et al., 2011). Thus, an 


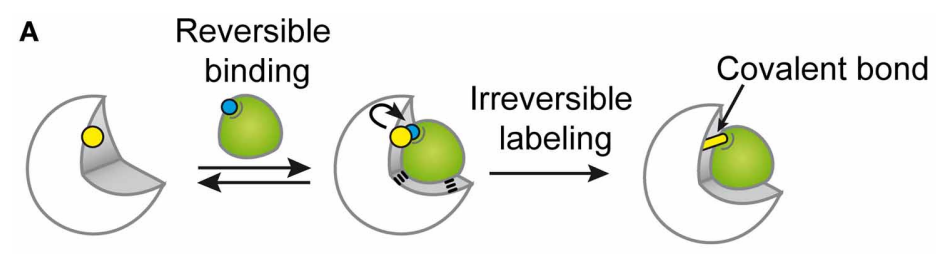

(Ni)

cysteine
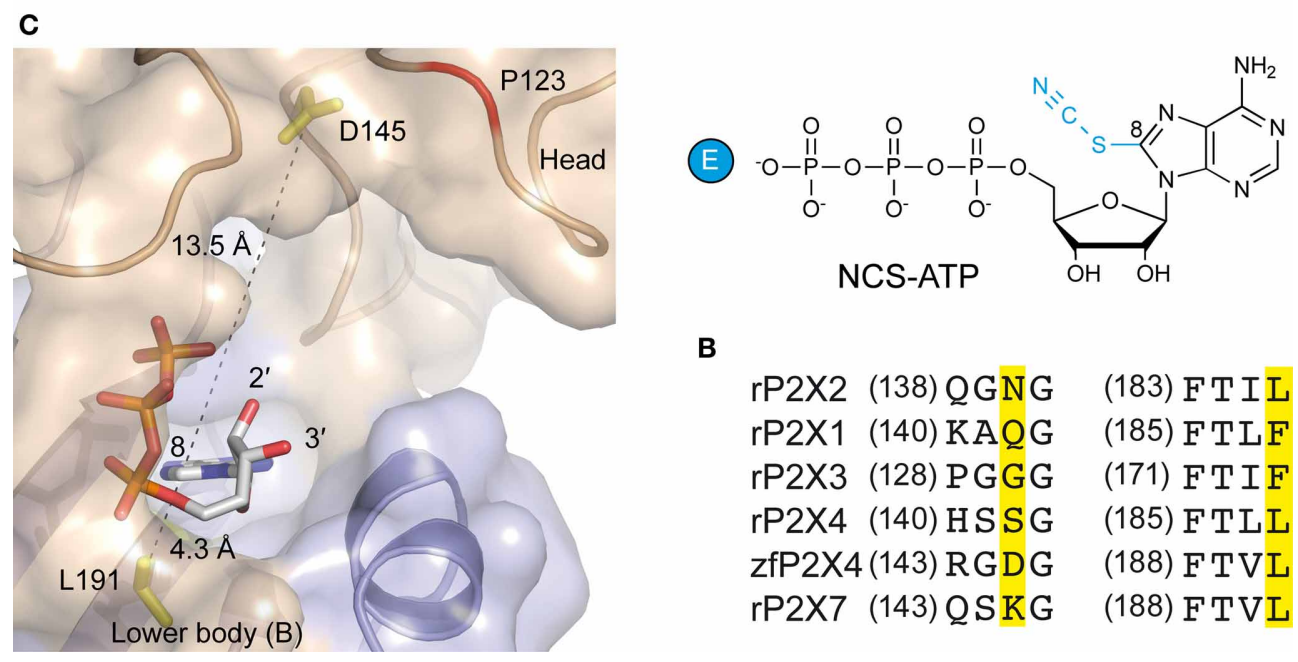

B

$\begin{array}{lll}\text { rP2X2 (138) QGNG } & \text { (183) FTIL } \\ \text { rP2X1 (140) KAQG } & \text { (185) FTLF } \\ \text { rP2X3 (128) PGGG } & \text { (171) FTIF } \\ \text { rP2X4 (140) HSSG } & \text { (185) FTLL } \\ \text { zfP2X4 (143) RGDG } & \text { (188) FTVL } \\ \text { rP2X7 (143) QSKG } & \text { (188) FTVL }\end{array}$

FIGURE 3 | Alternative methods to identify residues involved in the ATP-binding of P2X receptors. (A) Principle of engineered affinity labeling strategy. Chemical structures of the affinity label NCS-ATP and cysteine are shown. (B) Sequence alignment of

identified segments containing NCS-ATP-labeled residues in the P2X2 receptor (N140 and L186). (C) Spatial location of the corresponding labeled residues in the X-ray structure of the ATP-bound zfP2X4 receptor.

attractive hypothesis that deserves further experiments is that the $\mathrm{N} 140$-containing region contributes, in part, to the competitive antagonist binding site.

\section{SITE-DIRECTED FLUORESCENCE LABELING AND VOLTAGE-CLAMP FLUOROMETRY}

Another approach is the use of fluorescent strategies. Tetramethyl-Rhodamine-Maleimide (TMRM), a sulfhydrylreactive fluorescent dye on cysteine mutants, has the capacity to label cysteine-substituted residues that are accessible to the solvent (Lorinczi et al., 2012). The simultaneous measurement of ionic currents and fluorescence by voltage-clamp fluorometry, after site-directed fluorescence labeling, allowed to resolve ligand interactions and structural modifications which are associated with the conformational transitions of channels (Lorinczi et al., 2012). The effect of systematic substitution with cysteine residues in the cysteine-rich head domain of rP2X1 (A118 to I125) was examined because this region projects over the proposed ATP binding site (Kawate et al., 2009; Lorinczi et al., 2012). This work provided evidence that TMRM tethered to E122C reports $2^{\prime}, 3^{\prime}-O$-(4-benzoylbenzoyl)-ATP (Bz-ATP) binding, most probably by sensing $\mathrm{Bz}$ moiety of the ligand (Lorinczi et al., 2012). Because E122 is not aligned with a defined $z f P 2 X 4$ residue (Hattori and Gouaux, 2012), it would correspond to a region close to P123 in zfP2X4. Of note, the ATP-bound crystal structure shows that the solvent-exposed oxygen atoms $2^{\prime}$ et $3^{\prime}$ of the ribose point toward $\mathrm{P} 123$, a fact that is fully consistent with the hypothesis that tethered TMRM interacts directly with bound Bz-ATP (Figure 3C).

\section{PHOTOAFFINITY LABELING EXPERIMENTS}

Photoaffinity labeling is a powerful technique that is used extensively in other ligand-gated ion channel studies to probe important binding sites (Lemoine et al., 2012). At P2X receptors, the UV light-reactive ATP analog, ${ }^{32} \mathrm{P}$-2-azido ATP was employed to assess the effects of mutations of various residues on agonist binding (Roberts and Evans, 2007; Agboh et al., 2009; Roberts et al., 2009; Allsopp et al., 2011). The fact that photoincorporation of radiolabeled 2-azido ATP is reduced following mutations has contributed toward ascertaning the participation of residues K68, K70, K190, K309, and T186 to the coordination of ATP in the binding site of hP2X1 receptor (Roberts and Evans, 2007; Roberts et al., 2009; Allsopp et al., 2011). More recently, the partial agonist BzATP has been covalently incorporated by UV light into P2X receptors to investigate the relationship between ligand occupancy and channel gating (Bhargava et al., 2012; Browne and North, 2013). Although these studies did not identify labeled residues, they provided valuable information on the mechanism of ATP binding.

\section{X-RAY CRISTALLOGRAPHY: THE CONFIRMATION OF FUNCTIONAL AND BIOCHEMICAL STUDIES}

As previously indicated, the recent determination of X-ray structures of the zfP2X4 receptor (Kawate et al., 2009; Hattori and 
Gouaux, 2012) resolved in two states, the resting closed and open channel states, finally provided an unprecedented information not only regarding the three-dimensional shape of the receptor, but also on putative conformational modifications that couple ATP binding to channel opening. These data also provide a structural template for interpreting the huge amount of functional, mutagenesis, and biochemical data. In particular, as already reviewed, many key features of the binding site, including its interfacial location and ATP orientation as well as the identity of residues involved in ATP recognition, had been successfully anticipated from the biochemical and functional methods. These structural data thus represent a firm basis for understanding the mechanism by which agonists induce the opening of the ion channel.

\section{COUPLING ATP BINDING TO CHANNEL GATING}

Three ATP molecules bound to the trimeric receptor were resolved in the crystal structure (Hattori and Gouaux, 2012). Given that crystal structures represent snapshots among the multiple conformational states, this raises the question of whether $\mathrm{P} 2 \mathrm{X}$ receptor channel opening involves the occupancy of one, two, or three binding sites. Early work based on single-channel recordings suggested that channel activation proceeds through three ATP binding steps before opening and partially liganded channels do not appear to open (Ding and Sachs, 1999). Thus, channels only open after being fully liganded. However, more recent studies using concatenated subunits or kinetic models suggest that two ATP molecules are sufficient to activate P2X receptors (Yan et al., 2010; Stelmashenko et al., 2012). This conclusion supports previous study suggesting that heteromeric $\mathrm{P} 2 \mathrm{X} 2 / 3$ receptors are also activated by fewer than three agonist molecules (in this case $\alpha \beta$-methylene- $5^{\prime}$-ATP) (Jiang et al., 2003). Interestingly, there is now evidence that occupancy of one binding site of $\mathrm{P} 2 \mathrm{X} 2$ receptors does not produce detectable openings, but a conformational change that is spread to the second and third binding sites leading eventually to channel gating (Ding and Sachs, 1999; Jiang et al., 2011, 2012b; Browne et al., 2013). A functional significance of these results is that binding of the second and third ligand is strongly influenced by the binding of the first ligand revealing positive cooperativity.

The conformational change that follows binding of the first ligand suggests the existence of a transient, intermediate or primed closed state that precedes channel activation (Moffatt and Hume, 2007; Jiang et al., 2012b; Browne and North, 2013). The physiological relevance of this intermediate state is unclear, however, the fact that pyrimidine and diphosphate nucleotide analogs, which are not effective at $\mathrm{P} 2 \mathrm{X}$ receptors, become effective following binding of a low concentration of ATP implied that mixtures of nucleotides present in the extracellular milieu of the nervous system may have functional roles (Browne and North, 2013).

The ATP binding site is $\sim 40 \AA$ from the membrane-spanning segments, which constitute the ionic pore of $\mathrm{P} 2 \mathrm{X}$ receptors. The recent ATP-bound crystal structure, and previous studies utilizing normal mode analysis (Du et al., 2012; Jiang et al., 2012a), metalbridging experiments (Jiang et al., 2012a), electron microscopy (Roberts et al., 2012), and voltage-clamp fluorometry (Lorinczi et al., 2012), have now revealed a plausible activation mechanism that can be dissected into five steps (Figure 4): binding of ATP ${ }^{4-}$ (Li et al., 2013) to a pocket located at the interface between each subunit (first step) leads to the tightening of the head domain relative to the dorsal fin (second step). Because the ribose and adenine base interact hydrophobically with L217 and I232 (chain B), which are part of the dorsal fin, closure of the binding "jaw" induces the upward movement of the dorsal fin. Subsequently, the lower body, which is structurally coupled to the dorsal fin moves outward (third step), causing large expansion of the three lateral portals defined as "fenestrations" (fourth step). Finally, because the rigid $\beta$-sheet-folded lower body domain is directly coupled to the transmembrane helices 1 and 2, its outward flexing movement directly promotes channel gating by inducing the helices to

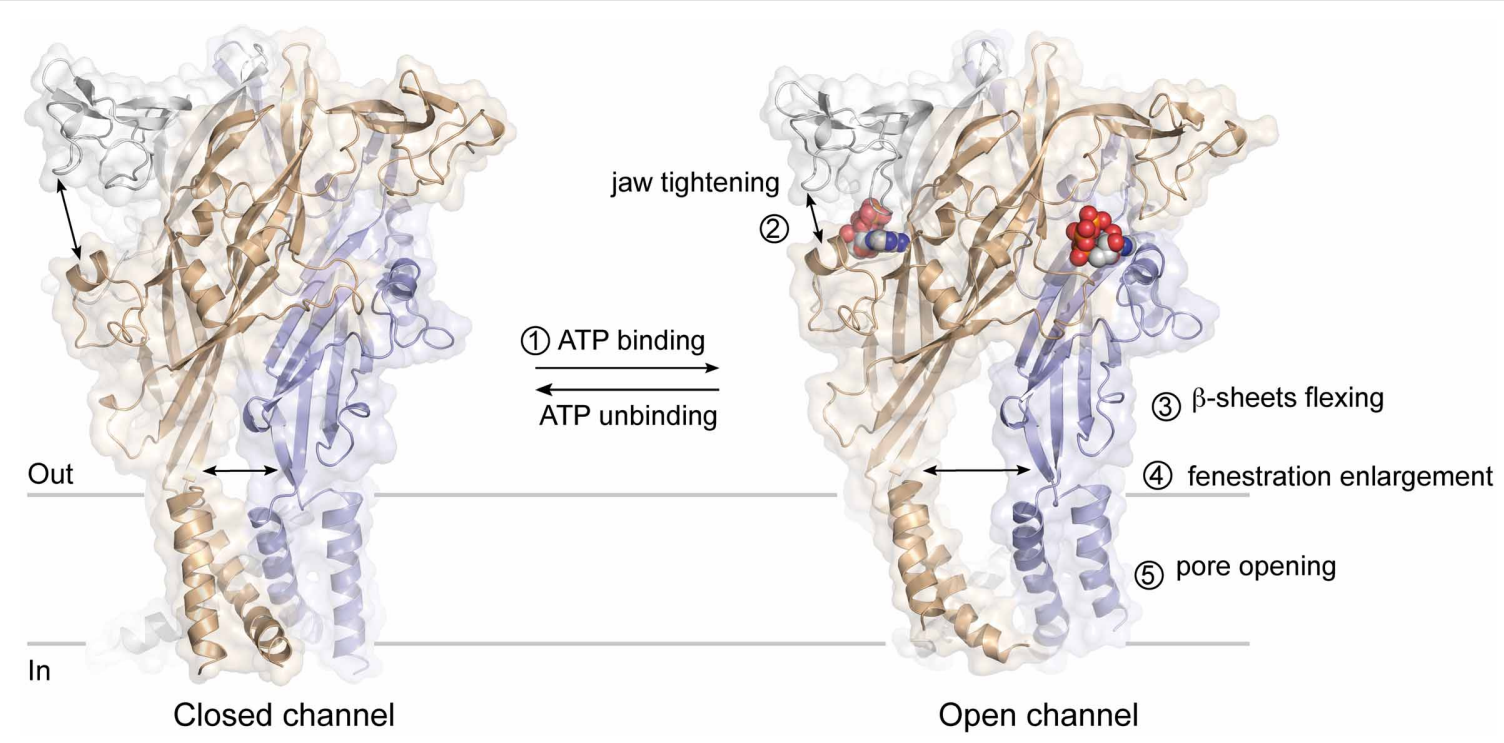

FIGURE 4 | Plausible mechanism of ATP-gated P2X receptors activation. The sequential steps leading to pore opening are indicated. 
expand the pore by $\sim 3 \AA$ (fifth step). This widening allows ions to cross the channel.

In this mechanism, major conformational changes take place at the subunit interface. Early studies have successfully anticipated the importance of these boundary contacts (Jiang et al., 2003, 2010; Nagaya et al., 2005; Marquez-Klaka et al., 2007), by restricting the relative movement of adjacent subunits by engineered disulfide bonds [for review see Jiang et al. (2013)]. These interfaces may be interesting targets for allosteric regulation of $\mathrm{P} 2 \mathrm{X}$ receptors.

\section{CONCLUDING REMARKS}

Extensive experimental works, including mutagenesis coupled to functional essays, engineered site-directed chemical labeling, fluorescence measurements, and resolution of the ATP-bound crystal structure, have provided a more precise vision of the ATP binding process and channel gating. This is probably a crucial step for the design of new competitive antagonists with therapeutic properties. Molecules that can selectively modulate $\mathrm{P} 2 \mathrm{X}$ receptors are needed because these receptors are involved in major neurological disorders. However, upon examining the ATP-binding site of $\mathrm{P} 2 \mathrm{X}$ receptors, it seems that an apparent conserved nature of the orthosteric sites may pose some difficulties to achieve strong subtype selectivity. The search for allosteric modulators would provide an alternative issue to this challenge.

\section{ACKNOWLEDGMENTS}

This work was supported by the CNRS, the University of Strasbourg and the Agence Nationale de la Recherche ANR 11 BSV5 001-01. The authors are indebted to Dr. Sheela Vyas for critical reading of the manuscript.

\section{REFERENCES}

Agboh, K. C., Powell, A. J., and Evans, R. J. (2009). Characterisation of ATP analogues to cross-link and label P2X receptors. Neuropharmacology 56, 230-236. doi: 10.1016/j.neuropharm.2008.05.018

Allsopp, R. C., El Ajouz, S., Schmid, R., and Evans, R. J. (2011). Cysteine scanning mutagenesis (residues Glu52-Gly96) of the human P2X1 receptor for ATP: mapping agonist binding and channel gating. J. Biol. Chem. 286, 29207-29217. doi: 10.1074/jbc.M111.260364

Ashcroft, F. M., and Gribble, F. M. (1998). Correlating structure and function in ATP-sensitive K+ channels. Trends Neurosci. 21, 288-294. doi: 10.1016/S01662236(98)01225-9

Bhargava, Y., Rettinger, J., and Mourot, A. (2012). Allosteric nature of P2X receptor activation probed by photoaffinity labelling. Br. J. Pharmacol. 167, 1301-1310. doi: 10.1111/j.1476-5381.2012.02083.x

Bo, X., Jiang, L. H., Wilson, H. L., Kim, M., Burnstock, G., Surprenant, A., et al. (2003). Pharmacological and biophysical properties of the human P2X5 receptor. Mol. Pharmacol. 63, 1407-1416. doi: 10.1124/mol.63.6.1407

Bodnar, M., Wang, H., Riedel, T., Hintze, S., Kato, E., Fallah, G., et al. (2011). Amino acid residues constituting the agonist binding site of the human P2X3 receptor. J. Biol. Chem. 286, 2739-2749. doi: 10.1074/jbc.M110.167437

Brandl, C. J., and Deber, C. M. (1986). Hypothesis about the function of membrane-buried proline residues in transport proteins. Proc. Natl. Acad. Sci. U.S.A. 83, 917-921. doi: 10.1073/pnas.83.4.917

Browne, L. E., Compan, V., Bragg, L., and North, R. A. (2013). P2X7 receptor channels allow direct permeation of nanometer-sized dyes. J. Neurosci. 33, 3557-3566. doi: 10.1523/JNEUROSCI.2235-12.2013

Browne, L. E., and North, R. A. (2013). P2X receptor intermediate activation states have altered nucleotide selectivity. J. Neurosci. 33, 14801-14808. doi: 10.1523/JNEUROSCI.2022-13.2013

Burnstock, G. (2008). Purinergic signalling and disorders of the central nervous system. Nat. Rev. Drug Discov. 7, 575-590. doi: 10.1038/nrd2605
Burnstock, G. (2012). Purinergic signalling: its unpopular beginning, its acceptance and its exciting future. Bioessays 34, 218-225. doi: 10.1002/bies.201100130

Cao, L., Young, M. T., Broomhead, H. E., Fountain, S. J., and North, R. A. (2007). Thr339-to-serine substitution in rat $\mathrm{P} 2 \mathrm{X} 2$ receptor second transmembrane domain causes constitutive opening and indicates a gating role for Lys308. J. Neurosci. 27, 12916-12923. doi: 10.1523/JNEUROSCI.4036-07.2007

Clyne, J. D., Wang, L. F., and Hume, R. I. (2002). Mutational analysis of the conserved cysteines of the rat P2X2 purinoceptor. J. Neurosci. 22, 3873-3880.

Coddou, C., Yan, Z., Obsil, T., Huidobro-Toro, J. P., and Stojilkovic, S. S. (2011). Activation and regulation of purinergic P2X receptor channels. Pharmacol. Rev. 63, 641-683. doi: 10.1124/pr.110.003129

Colquhoun, D. (1998). Binding, gating, affinity and efficacy: the interpretation of structure-activity relationships for agonists and of the effects of mutating receptors. Br. J. Pharmacol. 125, 924-947. doi: 10.1038/sj.bjp.0702164

Digby, H. R., Roberts, J. A., Sutcliffe, M. J., and Evans, R. J. (2005). Contribution of conserved glycine residues to ATP action at human P2X1 receptors: mutagenesis indicates that the glycine at position 250 is important for channel function. J. Neurochem. 95, 1746-1754. doi: 10.1111/j.1471-4159. 2005.03494.x

Ding, S., and Sachs, F. (1999). Single channel properties of P2X2 purinoceptors. J. Gen. Physiol. 113, 695-720. doi: 10.1085/jgp.113.5.695

Du, J., Dong, H., and Zhou, H. X. (2012). Gating mechanism of a P2X4 receptor developed from normal mode analysis and molecular dynamics simulations. Proc. Natl. Acad. Sci. U.S.A. 109, 4140-4145. doi: 10.1073/pnas.1119546109

Ennion, S., Hagan, S., and Evans, R. J. (2000). The role of positively charged amino acids in ATP recognition by human P2X(1) receptors. J. Biol. Chem. 275, 29361-29367. doi: 10.1074/jbc.M003637200

Ennion, S. J., and Evans, R. J. (2002). Conserved cysteine residues in the extracellular loop of the human P2X(1) receptor form disulfide bonds and are involved in receptor trafficking to the cell surface. Mol. Pharmacol. 61, 303-311. doi: 10.1124/mol.61.2.303

Ennion, S. J., Ritson, J., and Evans, R. J. (2001). Conserved negatively charged residues are not required for ATP action at P2X(1) receptors. Biochem. Biophys. Res. Commun. 289, 700-704. doi: 10.1006/bbrc.2001.6034

Evans, R. J. (2009). Orthosteric and allosteric binding sites of P2X receptors. Eur. Biophys. J. 38, 319-327. doi: 10.1007/s00249-008-0275-2

Evans, R. J. (2010). Structural interpretation of P2X receptor mutagenesis studies on drug action. Br. J. Pharmacol. 161, 961-971. doi: 10.1111/j.14765381.2010.00728.x

Fischer, W., Zadori, Z., Kullnick, Y., Groger-Arndt, H., Franke, H., Wirkner, K., et al. (2007). Conserved lysin and arginin residues in the extracellular loop of $\mathrm{P} 2 \mathrm{X}(3)$ receptors are involved in agonist binding. Eur. J. Pharmacol. 576, 7-17. doi: 10.1016/j.ejphar.2007.07.068

Foucaud, B., Perret, P., Grutter, T., and Goeldner, M. (2001). Cysteine mutants as chemical sensors for ligand-receptor interactions. Trends Pharmacol. Sci. 22, 170-173. doi: 10.1016/S0165-6147(00)01674-6

Fountain, S. J., and North, R. A. (2006). A C-terminal lysine that controls human P2X4 receptor desensitization. J. Biol. Chem. 281, 15044-15049. doi: 10.1074/jbc.M600442200

Fountain, S. J., Parkinson, K., Young, M. T., Cao, L., Thompson, C. R., and North, R. A. (2007). An intracellular P2X receptor required for osmoregulation in Dictyostelium discoideum. Nature 448, 200-203. doi: 10.1038/nature05926

Hattori, M., and Gouaux, E. (2012). Molecular mechanism of ATP binding and ion channel activation in P2X receptors. Nature 485, 207-212. doi: 10.1038 /nature11010

Hausmann, R., Gunther, J., Kless, A., Kuhlmann, D., Kassack, M. U., Bahrenberg, G., et al. (2013). Salt bridge switching from Arg290/Glu167 to Arg290/ATP promotes the closed-to-open transition of the P2X2 receptor. Mol. Pharmacol. 83, 73-84. doi: 10.1124/mol.112.081489

Jiang, L. H., Kim, M., Spelta, V., Bo, X., Surprenant, A., and North, R. A. (2003). Subunit arrangement in P2X receptors. J. Neurosci. 23, 8903-8910.

Jiang, L. H., Rassendren, F., Surprenant, A., and North, R. A. (2000). Identification of amino acid residues contributing to the ATP-binding site of a purinergic P2X receptor. J. Biol. Chem. 275, 34190-34196. doi: 10.1074/jbc.M005481200

Jiang, R., Lemoine, D., Martz, A., Taly, A., Gonin, S., Prado de Carvalho, L., et al. (2011). Agonist trapped in ATP-binding sites of the P2X2 receptor. Proc. Natl. Acad. Sci. U.S.A. 108, 9066-9071. doi: 10.1073/pnas.1102170108

Jiang, R., Martz, A., Gonin, S., Taly, A., de Carvalho, L. P., and Grutter, T. (2010). A putative extracellular salt bridge at the subunit interface contributes to the 
ion channel function of the ATP-gated P2X2 receptor. J. Biol. Chem. 285, 15805-15815. doi: 10.1074/jbc.M110.101980

Jiang, R., Taly, A., and Grutter, T. (2013). Moving through the gate in ATP-activated P2X receptors. Trends Biochem. Sci. 38, 20-29. doi: 10.1016/j.tibs.2012.10.006

Jiang, R., Taly, A., Lemoine, D., Martz, A., Cunrath, O., and Grutter, T. (2012a). Tightening of the ATP-binding sites induces the opening of $\mathrm{P} 2 \mathrm{X}$ receptor channels. ЕMBO J. 31, 2134-2143. doi: 10.1038/emboj.2012.75

Jiang, R., Taly, A., Lemoine, D., Martz, A., Specht, A., and Grutter, T. (2012b). Intermediate closed channel state(s) precede(s) activation in the ATP-gated P2X2 receptor. Channels (Austin) 6, 398-402. doi: 10.4161/chan.21520

Kaczmarek-Hajek, K., Lorinczi, E., Hausmann, R., and Nicke, A. (2012). Molecular and functional properties of $\mathrm{P} 2 \mathrm{X}$ receptors-recent progress and persisting challenges. Purinergic Signal. 8, 375-417. doi: 10.1007/s11302-012-9314-7

Kawate, T., Michel, J. C., Birdsong, W. T., and Gouaux, E. (2009). Crystal structure of the ATP-gated P2X(4) ion channel in the closed state. Nature 460, 592-598. doi: $10.1038 /$ nature 08198

Khakh, B. S., and North, R. A. (2012). Neuromodulation by extracellular ATP and P2X receptors in the CNS. Neuron 76, 51-69. doi: 10.1016/j.neuron.2012.09.024

Labro, A. J., Raes, A. L., Bellens, I., Ottschytsch, N., and Snyders, D. J. (2003). Gating of shaker-type channels requires the flexibility of S6 caused by prolines. J. Biol. Chem. 278, 50724-50731. doi: 10.1074/jbc.M306097200

Lemoine, D., Jiang, R., Taly, A., Chataigneau, T., Specht, A., and Grutter, T. (2012). Ligand-gated ion channels: new insights into neurological disorders and ligand recognition. Chem. Rev. 112, 6285-6318. doi: 10.1021/cr3000829

Li, M., Silberberg, S. D., and Swartz, K. J. (2013). Subtype-specific control of P2X receptor channel signaling by ATP and $\mathrm{Mg} 2+$. Proc. Natl. Acad. Sci. U.S.A. 110, E3455-E3463. doi: 10.1073/pnas.1308088110

Lorinczi, E., Bhargava, Y., Marino, S. F., Taly, A., Kaczmarek-Hajek, K., BarrantesFreer, A., et al. (2012). Involvement of the cysteine-rich head domain in activation and desensitization of the P2X1 receptor. Proc. Natl. Acad. Sci. U.S.A. 109, 11396-11401. doi: 10.1073/pnas.1118759109

Marquez-Klaka, B., Rettinger, J., Bhargava, Y., Eisele, T., and Nicke, A. (2007). Identification of an intersubunit cross-link between substituted cysteine residues located in the putative ATP binding site of the P2X1 receptor. J. Neurosci. 27, 1456-1466. doi: 10.1523/JNEUROSCI.3105-06.2007

Moffatt, L., and Hume, R. I. (2007). Responses of rat P2X2 receptors to ultrashort pulses of ATP provide insights into ATP binding and channel gating. J. Gen. Physiol. 130, 183-201. doi: 10.1085/jgp.200709779

Nagaya, N., Tittle, R. K., Saar, N., Dellal, S. S., and Hume, R. I. (2005). An intersubunit zinc binding site in rat P2X2 receptors. J. Biol. Chem. 280, 25982-25993. doi: 10.1074/jbc.M504545200

Nakazawa, K., and Ohno, Y. (1999). Neighboring glycine residues are essential for P2X2 receptor/channel function. Eur. J. Pharmacol. 370, R5-R6. doi: 10.1016/S0014-2999(99)00159-4

Roberts, J. A., Allsopp, R. C., El Ajouz, S., Vial, C., Schmid, R., Young, M. T., et al. (2012). Agonist binding evokes extensive conformational changes in the extracellular domain of the ATP-gated human P2X1 receptor ion channel. Proc. Natl. Acad. Sci. U.S.A. 109, 4663-4667. doi: 10.1073/pnas.1201872109

Roberts, J. A., Digby, H. R., Kara, M., El Ajouz, S., Sutcliffe, M. J., and Evans, R. J. (2008). Cysteine substitution mutagenesis and the effects of methanethiosulfonate reagents at $\mathrm{P} 2 \mathrm{X} 2$ and $\mathrm{P} 2 \mathrm{X} 4$ receptors support a core common mode of ATP action at P2X receptors. J. Biol. Chem. 283, 20126-20136. doi: 10.1074/jbc.M800294200

Roberts, J. A., and Evans, R. J. (2004). ATP binding at human P2X1 receptors. Contribution of aromatic and basic amino acids revealed using mutagenesis and partial agonists. J. Biol. Chem. 279, 9043-9055. doi: 10.1074/jbc.M308964200

Roberts, J. A., and Evans, R. J. (2005). Mutagenesis studies of conserved proline residues of human P2X receptors for ATP indicate that proline 272 contributes to channel function. J. Neurochem. 92, 1256-1264. doi: 10.1111/j.14714159.2004.02960.x

Roberts, J. A., and Evans, R. J. (2006). Contribution of conserved polar glutamine, asparagine and threonine residues and glycosylation to agonist action at human P2X1 receptors for ATP. J. Neurochem. 96, 843-852. doi: 10.1111/j.14714159.2005.03593.x

Roberts, J. A., and Evans, R. J. (2007). Cysteine substitution mutants give structural insight and identify ATP binding and activation sites at P2X receptors. J. Neurosci. 27, 4072-4082. doi: 10.1523/JNEUROSCI.2310-06.2007

Roberts, J. A., Valente, M., Allsopp, R. C., Watt, D., and Evans, R. J. (2009). Contribution of the region Glu181 to Val200 of the extracellular loop of the human P2X1 receptor to agonist binding and gating revealed using cysteine scanning mutagenesis. J. Neurochem. 109, 1042-1052. doi: 10.1111/j.14714159.2009.06035.x

Ruppelt, A., Ma, W., Borchardt, K., Silberberg, S. D., and Soto, F. (2001). Genomic structure, developmental distribution and functional properties of the chicken P2X(5) receptor. J. Neurochem. 77, 1256-1265. doi: 10.1046/j.14714159.2001.00348.x

Sansom, M. S., and Weinstein, H. (2000). Hinges, swivels and switches: the role of prolines in signalling via transmembrane alpha-helices. Trends Pharmacol. Sci. 21, 445-451. doi: 10.1016/S0165-6147(00)01553-4

Spitaler, M., Villunger, A., Grunicke, H., and Uberall, F. (2000). Unique structural and functional properties of the ATP-binding domain of atypical protein kinase C-iota. J. Biol. Chem. 275, 33289-33296. doi: 10.1074/jbc.M002742200

Stelmashenko, O., Lalo, U., Yang, Y., Bragg, L., North, R. A., and Compan, V. (2012). Activation of trimeric P2X2 receptors by fewer than three ATP molecules. Mol. Pharmacol. 82, 760-766. doi: 10.1124/mol.112.080903

Surprenant, A., and North, R. A. (2009). Signaling at purinergic P2X receptors. Annu. Rev. Physiol. 71, 333-359. doi: 10.1146/annurev.physiol.70.113006. 100630

Walker, J. E., Saraste, M., Runswick, M. J., and Gay, N. J. (1982). Distantly related sequences in the alpha- and beta-subunits of ATP synthase, myosin, kinases and other ATP-requiring enzymes and a common nucleotide binding fold. EMBO J. $1,945-951$.

Wilkinson, W. J., Jiang, L. H., Surprenant, A., and North, R. A. (2006). Role of ectodomain lysines in the subunits of the heteromeric P2X2/3 receptor. Mol. Pharmacol. 70, 1159-1163. doi: 10.1124/mol.106.026658

Wolf, C., Rosefort, C., Fallah, G., Kassack, M. U., Hamacher, A., Bodnar, M., et al. (2011). Molecular determinants of potent P2X2 antagonism identified by functional analysis, mutagenesis, and homology docking. Mol. Pharmacol. 79, 649-661. doi: 10.1124/mol.110.068700

Worthington, R. A., Smart, M. L., Gu, B. J., Williams, D. A., Petrou, S., Wiley, J. S., et al. (2002). Point mutations confer loss of ATP-induced human P2X(7) receptor function. FEBS Lett. 512, 43-46. doi: 10.1016/S0014-5793(01) 03311-7

Yamaguchi, H., Muth, J. N., Varadi, M., Schwartz, A., and Varadi, G. (1999). Critical role of conserved proline residues in the transmembrane segment 4 voltage sensor function and in the gating of L-type calcium channels. Proc. Natl. Acad. Sci. U.S.A. 96, 1357-1362. doi: 10.1073/pnas.96.4.1357

Yan, Z., Khadra, A., Li, S., Tomic, M., Sherman, A., and Stojilkovic, S. S. (2010). Experimental characterization and mathematical modeling of P2X7 receptor channel gating. J. Neurosci. 30, 14213-14224. doi: 10.1523/JNEUROSCI.239010.2010

Yan, Z., Liang, Z., Obsil, T., and Stojilkovic, S. S. (2006). Participation of the Lys313-Ile333 sequence of the purinergic P2X4 receptor in agonist binding and transduction of signals to the channel gate. J. Biol. Chem. 281, 32649-32659. doi: $10.1074 /$ jbc.M512791200

Yan, Z., Liang, Z., Tomic, M., Obsil, T., and Stojilkovic, S. S. (2005). Molecular determinants of the agonist binding domain of a P2X receptor channel. Mol. Pharmacol. 67, 1078-1088. doi: 10.1124/mol.104.010108

Zemkova, H., Yan, Z., Liang, Z., Jelinkova, I., Tomic, M., and Stojilkovic, S. S. (2007). Role of aromatic and charged ectodomain residues in the P2X(4) receptor functions. J. Neurochem. 102, 1139-1150. doi: 10.1111/j.14714159.2007.04616.x

Conflict of Interest Statement: The authors declare that the research was conducted in the absence of any commercial or financial relationships that could be construed as a potential conflict of interest.

Received: 08 October 2013; accepted: 07 December 2013; published online: 30 December 2013.

Citation: Chataigneau T, Lemoine D and Grutter T (2013) Exploring the ATP-binding site of P2X receptors. Front. Cell. Neurosci. 7:273. doi: 10.3389/fncel.2013.00273

This article was submitted to the journal Frontiers in Cellular Neuroscience.

Copyright () 2013 Chataigneau, Lemoine and Grutter. This is an open-access article distributed under the terms of the Creative Commons Attribution License (CC BY). The use, distribution or reproduction in other forums is permitted, provided the original author(s) or licensor are credited and that the original publication in this journal is cited, in accordance with accepted academic practice. No use, distribution or reproduction is permitted which does not comply with these terms. 